\title{
Uncured Polydimethylsiloxane as Binder Agent for Carbon Paste Electrodes: Application to the Quantification of Propranolol
}

\author{
Diele A. G. Araújo, ${ }^{a}$ Lauro A. Pradela-Filho, ${ }^{a}$ Allyson L. R. Santos, ${ }^{a}$ Anizio M. Faria,${ }^{a, b}$ \\ Regina M. Takeuchi, ${ }^{a, b}$ Hassan Karimi-Maleh ${ }^{c, d}$ and André L. Santos ${ }^{\circledR *, a, b}$ \\ ${ }^{a}$ Instituto de Química, Universidade Federal de Uberlândia, \\ Av. João Naves de Ávila, 2121, Santa Mônica, 38400-902 Uberlândia-MG, Brazil \\ ${ }^{b}$ Instituto de Ciências Exatas e Naturais do Pontal, Universidade Federal de Uberlândia, \\ Rua 20, 1600, Tupã, 38304-402 Ituiutaba-MG, Brazil \\ 'Department of Chemical Engineering, Laboratory of Nanotechnology, \\ Quchan University of Technology, 94771-67335 Quchan, Iran \\ ${ }^{d}$ Department of Applied Chemistry, University of Johannesburg, \\ 2006 Johannesburg, South Africa
}

\begin{abstract}
This study describes the use of uncured polydimethylsiloxane (PDMS) as a binder agent to prepare carbon paste electrodes (CPEs). A comparative study between the properties of CPEs prepared with PDMS and mineral oil $\mathrm{Nujol}^{\circledR}$, the most common binder agent for CPEs, was carried out. Cyclic voltammetry, electrochemical impedance spectroscopy, and chronoamperometry showed that PDMS-CPEs presented higher electrical conductivity, active electrochemical area, and wider useful potential window compared with $\mathrm{Nujol}^{\circledR}{ }^{\circledR} \mathrm{CPEs}$. Moreover, PDMS-CPEs were more stable in aqueous mixtures containing $50 \%(\mathrm{v} / \mathrm{v})$ of ethanol or methanol than $\mathrm{Nujol}^{\circledR}{ }^{\circledR} \mathrm{CPEs}$. PDMS-CPEs have also provided higher sensitivity and lower limit of detection to propranolol than $\mathrm{Nujol}^{\circledR}$-CPE. Therefore, this study demonstrated that PDMS is a promising alternative binder agent able to produce CPEs with superior chemical/electrochemical stability and improved analytical performance.
\end{abstract}

Keywords: polydimethylsiloxane, voltammetry, drug analysis

\section{Introduction}

Carbon paste electrodes (CPEs) are composed by a mixture between graphite powder and a binder agent, usually a mineral oil such as Nujol ${ }^{\circledR}$. Currently, CPEs are well-established electrode materials widely used in electroanalysis. ${ }^{1}$ The low-cost and versatility of CPEs are key factors in making them very popular electrodes which are able to quantify both organic and inorganic analytes., ${ }^{2,3}$ Since their introduction in 1958 by Adams, ${ }^{4}$ CPEs have remarkably evolved mainly due to the introduction of modern carbon-based materials, such as carbon nanotubes, graphene, carbon nanofibers, etc. ${ }^{5}$ The use of chemical modifiers has also brought impressive advances to CPEs and the easiness of modification is another attractive feature of these electrodes. A chemically modified CPE is obtained by

*e-mail: alsantos@ufu.br the simple addition of the chemical modifier to the mixture between graphite powder and the binder agent. Several chemical modifiers have been used such as ion exchange materials, ${ }^{6,7}$ silica, and organofunctionalized silicas, ${ }^{8-11}$ metallic nanoparticles, ${ }^{12,13}$ oxides $^{14}$ and complexes, ${ }^{15,16}$ carbon nanotubes, ${ }^{17}$ etc. These materials have allowed the preparation of CPEs with superior analytical performance extending their application to trace analysis of different kinds of analytes, such as metal ions, ${ }^{18,19}$ drugs, ${ }^{20,21}$ organic pollutants ${ }^{22}$ and biologically important compounds. ${ }^{23}$

Despite the success of CPEs in electroanalysis, these electrodes present some unfavorable characteristics, such as instability in organic solvents, aging effect, and low mechanical strength. ${ }^{5}$ Therefore, the applicability of CPEs is restricted to freshly prepared electrodes in aqueous solutions at static conditions. The binder agent is the responsible for these drawbacks, which has stimulated the search for new materials able to produce more stable 
CPEs, such as solid paraffin, ${ }^{24,25}$ polyurethane, ${ }^{26-29}$ epoxy resins, ${ }^{30,31}$ Teflon $^{\circledR},{ }^{32,33}$ etc.

The hydrophobic nature of carbon pastes is their most important physicochemical property regarding its influence on the analytical performance of the final CPE. ${ }^{5}$ Highly hydrophobic CPEs are expected to provide a poor response for hydrophilic species which will be repelled from the electrode surface. On the other hand, these CPEs have a high performance to the quantification of hydrophobic analytes, even being able to extract them from aqueous solutions. ${ }^{5}$ The grade of hydrophobicity of the CPE is directly related to the binder agent. Thus, besides connecting the conductive carbon particles giving a paste consistency, the binder agent also affects the main physicochemical and electrochemical properties of the CPEs. Therefore, the search for new binder agents is crucial not only to produce mechanically stable CPEs but also to achieve superior analytical/electrochemical performance.

Silicone oils and silicone rubbers, which are polymerized siloxanes containing organic side chains, are very attractive binder agents successfully used in electroanalysis. ${ }^{34-36}$ They present several similar properties to mineral oil, such as chemical inertness, water insolubility, insulating nature and low toxicity. ${ }^{5}$ However, comparing with mineral oil, silicone oils are usually more viscous, leading to the formation of more rigid and compact carbon pastes. ${ }^{5}$ Polydimethylsiloxane (PDMS) $\left[\left(\mathrm{CH}_{3}\right)_{2} \mathrm{SiO}\right]_{\mathrm{n}}$ is the most widely used polymer in commercial silicone elastomers. ${ }^{37}$ Despite being a common and inexpensive material, only a few reports describing the use of PDMS as a binder agent for CPEs are found in the literature. Kulys et al.$^{38}$ evaluated the applicability of a PDMS-based CPE doped with glucose oxidase as a biosensor for glucose determination. The authors found that PDMS-CPEs presented high electric conductivity and a good performance for glucose determination. Wang et al. ${ }^{39}$ also prepared a glucose biosensor employing a PDMS-CPE, and they observed that PDMS was superior to poly(chlorotrifluoroethylene) (Kel-F) oil. Silva et al. ${ }^{40}$ used a composite electrode containing graphite and amino-functionalized PDMS for the determination of $\mathrm{Cu}^{2+}$ with attractive results. Composites carbon-PDMS have also been employed to prepare electrodes for applications in microfluidics devices. ${ }^{41,42}$ However, for these applications in microfluidics, curing agents were always used. To the best of our knowledge, no reports are presenting a systematic comparison between conventional CPEs prepared with mineral oil $\left(\mathrm{Nujol}^{\circledR}\right)$ and uncured PDMS-CPEs or applying it for drug analysis.

Propranolol (PROP), 1-(isopropylamino)3-(naphthalen-1-yloxy)propan-2-ol (Figure 1), is one of the drugs from the $\beta$-blockers group, used for arterial hypertension treatment.

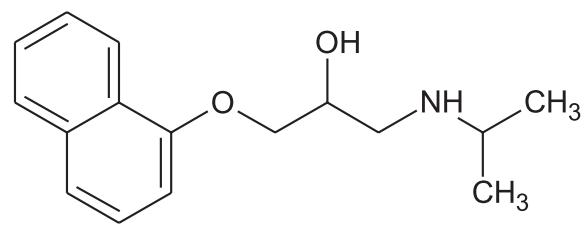

Figure 1. Chemical structure of PROP.

Analytical methods for quantification of PROP include chromatographic, ${ }^{43}$ spectrophotometric, ${ }^{44}$ colorimetric ${ }^{45}$ and electrophoretic ${ }^{46}$ methods. Electrochemical methods are also found in the literature. Chemically modified electrodes ${ }^{47-51}$ and $\mathrm{CPEs}^{34,52}$ are commonly used to detect this specie. Therefore, regarding the considerable number of electroanalytical methods for PROP determination, this drug can be used as a model analyte to evaluate the analytical performance of PDMS-CPEs. Thus, the objective of this work was to evaluate the properties of uncured PDMS as a binder agent and compare its electrochemical performance with $\mathrm{Nujol}^{\circledR}$ in both aqueous and aqueous/ organic solvents mixtures. Moreover, the analytical performance of PDMS-CPE for PROP determination was evaluated.

\section{Experimental}

Reagents and solutions

All the chemical reagents used in this study were analytical grade, and they were used as received. The aqueous solutions were prepared with ultrapure water (ASTM type I), with resistivity $\geq 18 \mathrm{M} \Omega \mathrm{cm}$, obtained from a Megapurity ${ }^{\circledR}$ (Billerica, USA) system. Ethanol (Vetec, Rio de Janeiro, Brazil) and methanol (J.T. Baker, Mexico DF, Mexico) were used in the voltammetric studies performed in the mixtures aqueous solution/organic solvent. The electrochemical measurements performed in the presence of the electrochemical probe potassium hexacyanoferrate (II) were conducted in $1.0 \mathrm{mmol} \mathrm{L}^{-1} \mathrm{~K}_{4}\left[\mathrm{Fe}(\mathrm{CN})_{6}\right]$ (Vetec, Rio de Janeiro, Brazil) and $1.0 \mathrm{~mol} \mathrm{~L}^{-1} \mathrm{KCl}$ (Vetec, Rio de Janeiro, Brazil) as supporting electrolyte.

The supporting electrolyte used in the voltammetric studies carried out in the presence of PROP was the BrittonRobinson (BR) buffer solution. BR buffer solutions were prepared with potassium dihydrogen phosphate, boric acid, and acetic acid, all of them with a final concentration of $0.04 \mathrm{~mol} \mathrm{~L}^{-1} .6 \mathrm{~mol} \mathrm{~L}^{-1} \mathrm{KOH}$ or $6 \mathrm{~mol} \mathrm{~L}^{-1} \mathrm{HCl}$ were used to adjust the $\mathrm{pH}$ of the $\mathrm{BR}$ buffer solution without ionic strength adjustment. It was necessary to use the $6 \mathrm{~mol} \mathrm{~L}^{-1}$ 
$\mathrm{HCl}$ solution since $\mathrm{KH}_{2} \mathrm{PO}_{4}$ replaced the $\mathrm{H}_{3} \mathrm{PO}_{4}$ in the preparation of the $\mathrm{BR}$ buffer solution, leading to an initial $\mathrm{pH}$ of 5.4. All the chemicals used to prepare BR buffer solutions were purchased from Vetec (Rio de Janeiro, Brazil). Stock solutions of PROP were daily prepared by dissolving $99.8 \%$ purity (pharmaceutical grade) propranolol hydrochloride (All Chemistry, São Paulo, Brazil) in the BR buffer solution.

Graphite powder with particles size $<20 \mu \mathrm{m}$ (Sigma, St. Louis, USA) was used to prepare the CPEs. $\mathrm{Nujol}^{\circledR}{ }^{\circledR} \mathrm{CPEs}$, used for comparative purposes, were prepared with mineral oil Nujol ${ }^{\circledR}$ purchased from Sigma (St. Louis, USA). PDMS-CPEs were prepared with trimethylsiloxy terminated polydimethylsiloxane with a viscosity of 10,000 centistokes purchased from Petrarch Systems Inc. (Pennsylvania, USA).

\section{Apparatus}

Voltammetric and electrochemical impedance spectroscopy (EIS) measurements were performed with a $\mu$ Autolab type III (Metrohm Autolab, Utrecht, Netherlands) and an AUTOLAB PGSTAT 204 (Metrohm Autolab, Utrecht, Netherlands), respectively. Both instruments were interfaced to a personal computer and controlled by NOVA 2.1 software. All the electrochemical experiments were conducted in a single-compartment electrochemical cell containing $10.0 \mathrm{~mL}$ of the supporting electrolyte solution. $\mathrm{An} \mathrm{Ag} / \mathrm{AgCl}, \mathrm{KCl}_{\text {(sat) }}$ and a $0.5 \mathrm{~mm}$ diameter platinum wire were used as the reference and the auxiliary electrode, respectively. The working electrodes were the $\mathrm{Nujol}^{\circledR}{ }_{-} \mathrm{CPE}$ or PDMS-CPE. All the electrochemical experiments were performed at room temperature.

A pH meter (Hanna Instruments, Woonsocket, USA) model HI 3221 coupled to a combined glass electrode was used for $\mathrm{pH}$ measurements. Scanning electron microscopy (SEM) images of the CPEs were acquired with a scanning electron microscope model VEGA3-Tescan (Brnokohoutovice, Czech Republic) operated at $20 \mathrm{kV}$. All the samples were sputter-coated with gold before the SEM analysis. Spectrophotometric determination of PROP was performed with a double beam UV-Visible spectrophotometer (Lambda 25, PerkinElmer Ltd., Beaconsfield, UK) according to the procedure described in the Brazilian Pharmacopoeia. ${ }^{53}$

\section{Electrode preparation}

PDMS-CPEs were prepared by hand-mixing the graphite powder and PDMS in the proportion $80: 20 \%(\mathrm{~m} / \mathrm{m})$, respectively. This mixture was ground with a mortar and pestle for $10 \mathrm{~min}$, the time necessary to achieve a paste with uniform consistency. This same procedure was adopted to prepare the $\mathrm{Nujol}^{\circledR}{ }^{\circledR}$-CPEs. The carbon pastes were placed in an insulin syringe (internal diameter of $5 \mathrm{~mm}$ ) containing a copper rod as the electrical contact. Electrode surface renewing was provided by pushing a small amount of the paste out of the syringe. The excess of the carbon paste was removed by polishing the electrode in A4 paper $80 \mathrm{~g} \mathrm{~m}^{-2}$. Finally, the CPEs were hand-polished on a weighing paper until a smooth surface was obtained.

\section{Analytical procedure and sample analysis}

PROP determination was carried out by differential pulse voltammetry (DPV) using $0.04 \mathrm{~mol} \mathrm{~L}^{-1} \mathrm{BR}$ buffer solution $(\mathrm{pH}=2.0)$ as supporting electrolyte. Analytical curves for PROP were constructed by adding PROP standard solutions at different concentrations to the electrochemical cell. For each PROP concentration, voltammetric measurements were performed in triplicate. After each voltammetric scan, the electrode surface was successively polished with A4 paper and weighing paper.

Samples of pharmaceutical formulations containing $40 \mathrm{mg}$ of PROP per tablet were acquired from local drugstores. 20 tablets of each sample were ground with a mortar and pestle, and a portion of approximately $32 \pm 0.1 \mathrm{mg}$ was transferred to a $50.0 \mathrm{~mL}$ volumetric flask, and the volume was completed with the supporting electrolyte. One aliquot of $500 \mu \mathrm{L}$ of this solution was transferred to the electrochemical cell containing $10.0 \mathrm{~mL}$ of the supporting electrolyte. DP voltammograms were recorded, and the amount of PROP was determined by using the analytical curve equation. These samples were also analyzed by UV-Vis spectrophotometry, according to the procedure described in the Brazilian Pharmacopoeia. ${ }^{53}$

\section{Results and Discussion}

\section{PDMS-CPE characterization}

The paste composition has a substantial effect on the properties of the final CPE. Higher binder contents improve the mechanical strength; however, lead to low electrical conductivity and poor electrochemical performance. We have observed that CPEs containing $20 \%(\mathrm{~m} / \mathrm{m})$ of the binder agent $\left(\mathrm{Nujol}^{\circledR}\right.$ or PDMS $)$ provided both adequate mechanical strength and electrochemical performance. Therefore, this composition was used in all the subsequent experiments. This result agrees with the literature, ${ }^{6,34,35,54,55}$ which reports that CPEs with binder contents of $20-30 \%(\mathrm{~m} / \mathrm{m})$ are the most appropriate for electroanalytical applications. 
SEM images for PDMS and $\mathrm{Nujol}^{\circledR}-\mathrm{CPEs}$ are presented in Figure 2.
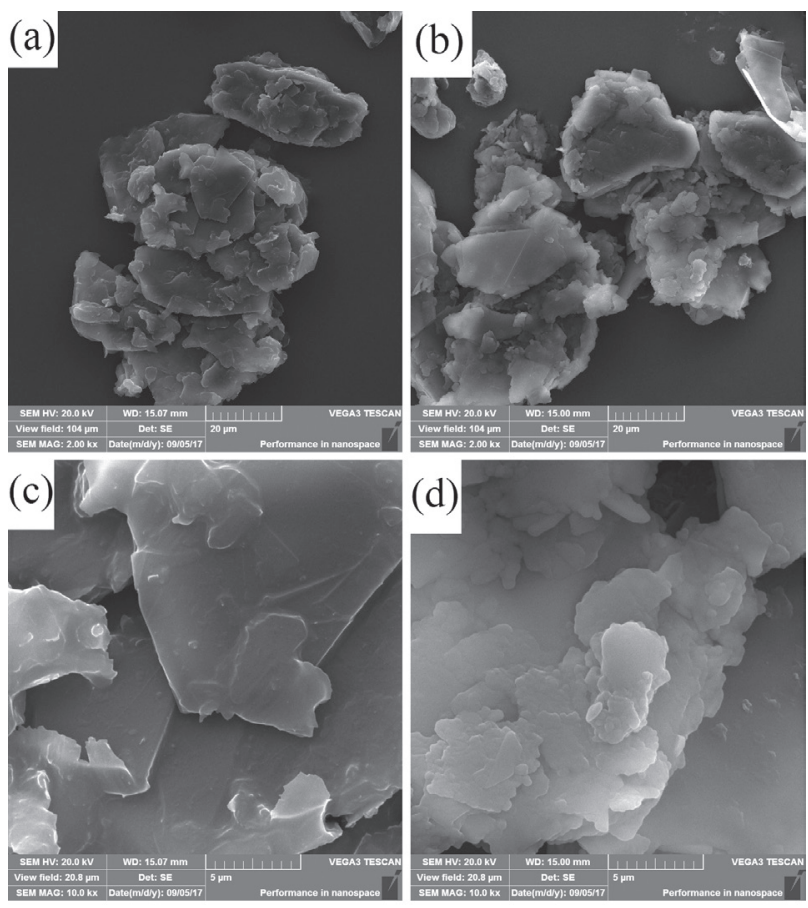

Figure 2. SEM images for (a, c) PDMS-CPE and (b, d) $\mathrm{Nujol}^{\circledR}$-CPE.

From Figure 2 it can be observed that PDMS-CPE and $\mathrm{Nujol}^{\circledR}{ }^{\circledR} \mathrm{CPE}$ present similar morphologies with almost the same roughness. Despite this similarity, it was observed that PDMS-CPE was more rigid and showed a brighter surface than $\mathrm{Nujol}^{\circledR}{ }^{\circledR} \mathrm{CPE}$, suggesting that this electrode has better

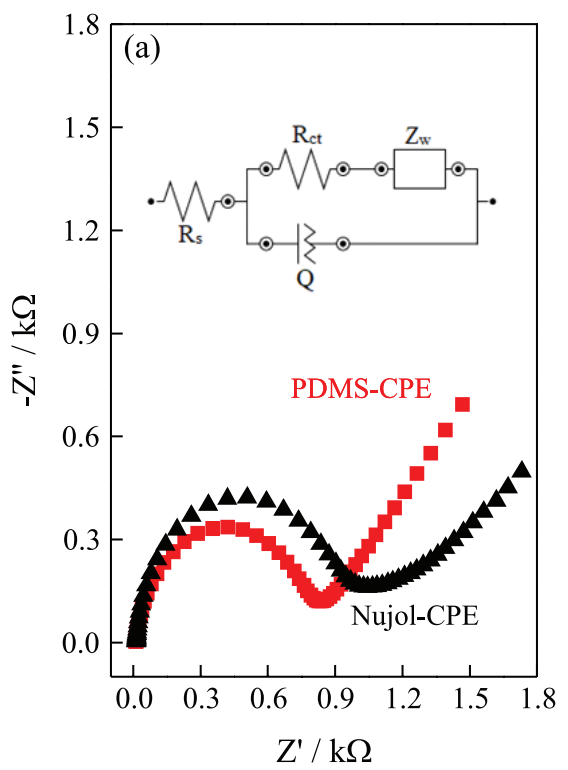

mechanical strength and electrical conductivity. EIS and cyclic voltammetry experiments were conducted in the presence of the electrochemical probe $\left[\mathrm{Fe}(\mathrm{CN})_{6}\right]^{4}$ and the results are presented in Figure 3.

The semicircles observed at high frequencies in the Nyquist plots (Figure 3a) provide information about the charge transfer resistance $\left(R_{c t}\right)$ and solution resistance $\left(R_{s}\right)$. $\mathrm{R}_{\mathrm{ct}}$ can be estimated as the diameter of the semicircle. As can be observed in Figure 3a, the PDMS-CPE provided the smallest diameter, indicating this electrode presents a lower $\mathrm{R}_{\mathrm{ct}}$ compared with $\mathrm{Nujol}^{\circledR}$-CPE. The Nyquist plots presented in Figure $3 \mathrm{a}$ were best fitted with the equivalent circuit model presented in the inset of Figure 3a. The $\mathrm{R}_{\mathrm{ct}}$ values obtained for PDMS-CPE and Nujol ${ }^{\circledR}$-CPE were 0.768 and $0.986 \mathrm{k} \Omega$, respectively. The values of the other components of the equivalent circuit are shown in Table S1 (presented in Supplementary Information (SI)). PDMS-CPE also presented the smallest peak separation $\left(\Delta \mathrm{E}_{\mathrm{p}}\right)$ in the cyclic voltammograms recorded in the presence of $\left[\mathrm{Fe}(\mathrm{CN})_{6}\right]^{4}$. $\Delta \mathrm{E}_{\mathrm{p}}$ values for PDMS-CPE and Nujol ${ }^{\circledR}$-CPEs were 86 and $125 \mathrm{mV}$, respectively. Therefore, the results obtained from EIS and cyclic voltammetry demonstrate that PDMS-CPE is a more conductive material than $\mathrm{Nujol}^{\circledR}-\mathrm{CPE}$.

Cyclic voltammograms were recorded with the PDMS-CPE in the presence of $1.0 \mathrm{mmol} \mathrm{L}^{-1}\left[\mathrm{Fe}(\mathrm{CN})_{6}\right]^{4-}$ at different scan rates $(v)$ (Figure S1, SI section). The plots of anodic peak current $\left(\mathrm{i}_{\mathrm{pa}}\right)$ and cathodic peak current $\left(\mathrm{i}_{\mathrm{pc}}\right) v s . v^{1 / 2}$ were linear from 25 to $200 \mathrm{mV} \mathrm{s}^{-1}$, according to the equations: $\mathrm{i}_{\mathrm{pa}}(\mu \mathrm{A})=3.9+1.9 \mathrm{v}^{1 / 2}\left(\mathrm{mV} \mathrm{s}^{-1}\right)^{1 / 2}$, determination coefficient $\left(\mathrm{r}^{2}\right)=0.995$ and $\mathrm{i}_{\mathrm{pc}}(\mu \mathrm{A})=-1.82-4.86 \mathrm{v}^{1 / 2}\left(\mathrm{mV} \mathrm{s}^{-1}\right)^{1 / 2}$,

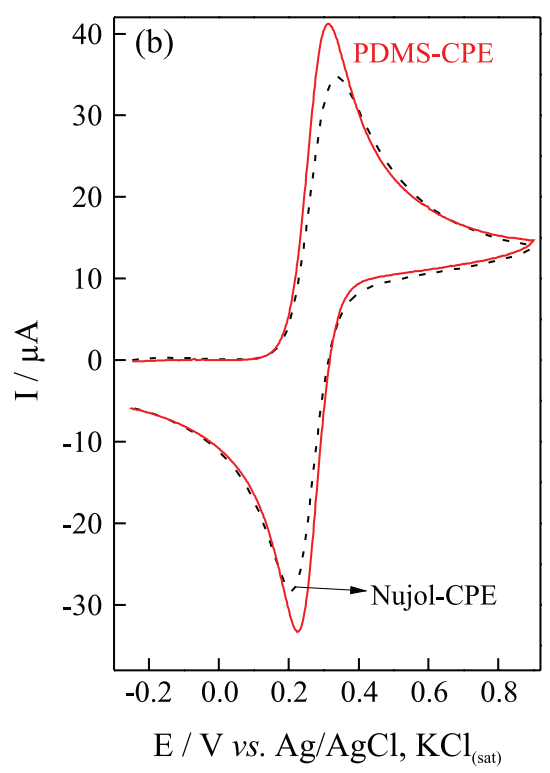

Figure 3. (a) Nyquist plot recorded in $1.0 \mathrm{~mol} \mathrm{~L}^{-1} \mathrm{KCl}$ in the presence of $5.0 \mathrm{mmol} \mathrm{L}^{-1}\left[\mathrm{Fe}(\mathrm{CN})_{6}\right]^{4}$. Frequency range from 0.1 to $1 \times 10^{5} \mathrm{~Hz}$, amplitude $=10 \mathrm{mV}$, DC potential: $0.27 \mathrm{~V}$; (b) cyclic voltammograms recorded in $1.0 \mathrm{~mol} \mathrm{~L}^{-1} \mathrm{KCl}$ in the presence of $1.0 \mathrm{mmol} \mathrm{L}^{-1}\left[\mathrm{Fe}(\mathrm{CN})_{6}\right]^{4}, \mathrm{~V}=100 \mathrm{mV} \mathrm{s}^{-1}$. Figure $3 \mathrm{a}$ inset is the equivalent circuit model used to fit the Nyquist plots. $\mathrm{R}_{\mathrm{s}}$ : solution resistance; $\mathrm{R}_{\mathrm{ct}}$ : charge transfer resistance; $\mathrm{Q}$ : constant phase element; $\mathrm{Z}_{\mathrm{w}}$ : Warburg impedance. 
$\mathrm{r}^{2}=0.997$, indicating a diffusional-controlled process, which is the expected behavior for this electrochemical probe. $\Delta \mathrm{E}_{\mathrm{p}}$ ranged from 86 to $166 \mathrm{mV}$ by increasing $\mathrm{v}$, and these values are in close agreement with the work by Brun et al. ${ }^{41}$ who observed $\Delta \mathrm{E}_{\mathrm{p}}=177 \mathrm{mV}$ for a plasmapretreated carbon-PDMS composite electrode. $\Delta \mathrm{E}_{\mathrm{p}}$ values for $\left[\mathrm{Fe}(\mathrm{CN})_{6}\right]^{4-}$ obtained with composite electrodes usually exceed the expected for a one-electron reversible electrochemical process $\left(\Delta \mathrm{E}_{\mathrm{p}}=59 \mathrm{mV}\right.$ at $\left.298.15 \mathrm{~K}\right){ }^{56}$ These higher $\Delta \mathrm{E}_{\mathrm{p}}$ values can be ascribed to the less conductive nature of the composite electrodes compared with conventional Pt or glassy carbon electrodes. ${ }^{57}$

Cyclic voltammograms were also recorded with PDMS-CPE at different concentrations of $\left[\mathrm{Fe}(\mathrm{CN})_{6}\right]^{4-}$ (Figure S2, SI section). The plots of $\mathrm{i}_{\mathrm{pa}}$ and $\mathrm{i}_{\mathrm{pc}} v s$. the concentration of $\left[\mathrm{Fe}(\mathrm{CN})_{6}\right]^{4-}$ were linear from 0.2 to $1.0 \mathrm{mmol} \mathrm{L}^{-1}$, according to the equations: $\mathrm{i}_{\mathrm{pa}}(\mu \mathrm{A})=0.69+20.86 \mathrm{C}_{\left[\mathrm{Fe}(\mathrm{CN})_{6}\right]^{4-}}\left(\mathrm{mmol} \mathrm{L}^{-1}\right), \mathrm{r}^{2}=0.999$ and $\mathrm{i}_{\mathrm{pc}}(\mu \mathrm{A})=-1.06-19.80 \mathrm{C}_{\left[\mathrm{Fe}(\mathrm{CN})_{6}\right]^{4-}}\left(\mathrm{mmol} \mathrm{L}^{-1}\right), \mathrm{r}^{2}=0.999$. The linear coefficients for these plots were close to zero and the angular coefficients ratio was close to 1 , which is a typical behavior for a diffusion-controlled reversible electrochemical process. These results demonstrate that the PDMS-CPE was stable in the time scale of this experiment, presenting a very good linearity and an electrochemical behavior close to the ideally expected for the $\left[\mathrm{Fe}(\mathrm{CN})_{6}\right]^{4-}$ electrochemical probe. Inter and intra-day precisions were evaluated by the relative standard deviation (RSD) for $\mathrm{i}_{\mathrm{pa}}$ from cyclic voltammograms recorded with PDMS-CPE in the presence of $1.0 \mathrm{mmol} \mathrm{L}^{-1}\left[\mathrm{Fe}(\mathrm{CN})_{6}\right]^{4-}$ and they were 3 and $9 \%(\mathrm{n}=3)$, respectively.

The active electrochemical areas of PDMS and $\mathrm{Nujol}^{\circledR}$-CPE were determined by chronoamperometry using $\left[\mathrm{Fe}(\mathrm{CN})_{6}\right]^{4-}$ as electroactive specie. ${ }^{57,58}$ Cottrell's equation was employed with the following parameters: the number of electrons transferred $=1$; the Faraday constant $=96,485 \mathrm{C} \mathrm{mol}^{-1}$; concentration of $\left[\mathrm{Fe}(\mathrm{CN})_{6}\right]^{4-}=1.0 \times 10^{-5} \mathrm{~mol} \mathrm{~cm}^{-3}$ and average diffusion coefficient of $\left[\mathrm{Fe}(\mathrm{CN})_{6}\right]^{4-}$ in $1.0 \mathrm{~mol} \mathrm{~L}{ }^{-1}$ $\mathrm{KCl}=6.58 \times 10^{-6} \mathrm{~cm}^{2} \mathrm{~s}^{-1} .{ }^{59}$ The chronoamperometric curves and the respective I vs. $\mathrm{t}^{-1 / 2}$ plots are presented in Figure S3 (SI section). PDMS-CPE and $\mathrm{Nujol}^{\circledR}{ }^{-\mathrm{CPE}}$ were placed in identical cylindrical holders with an inner diameter of $5 \mathrm{~mm}$. Thus, both electrodes have a geometric area of $0.196 \mathrm{~cm}^{2}$. The electrochemical active areas for $\mathrm{Nujol}^{\circledR}{ }_{-} \mathrm{CPE}$ and PDMS-CPEs were $0.183 \pm 0.003 \mathrm{~cm}^{2}$ $(\mathrm{n}=3)$ and $0.240 \pm 0.002 \mathrm{~cm}^{2}(\mathrm{n}=3)$, respectively. Therefore, the roughness factors, i.e., the ratio between the active electrochemical area and the geometric area were $0.93 \pm 0.02$ and $1.22 \pm 0.01$ for $\mathrm{Nujol}^{\circledR}{ }_{-} \mathrm{CPE}$ and PDMS-CPE, respectively. Despite the apparent similarity in the roughness of PDMS-CPE and Nujol ${ }^{\circledR}$-CPE (Figure 2), the active electrochemical area of PDMS-CPE is higher. Similar behavior was observed by Oliveira et al. ${ }^{35}$ for silicone-rubber CPEs. These authors have studied several CPE compositions, and SEM images revealed that all of them presented almost the same morphology and roughness. However, CPEs containing 30\% of siliconerubber showed the highest active electrochemical area, which was ascribed to the highest electrical conductivity presented by this composition. Therefore, the higher electrical conductivity of PDMS-CPE compared with $\mathrm{Nujol}^{\circledR}{ }_{-} \mathrm{CPE}$ could be responsible for its higher active electrochemical area despite the apparent similarity in the roughness of PDMS-CPE and $\mathrm{Nujol}^{\circledR}{ }_{-}$-CPE.

The useful potential window for PDMS and $\mathrm{Nujol}^{\circledR}{ }_{-} \mathrm{CPE}$ was determined by cyclic voltammetry in $0.1 \mathrm{~mol} \mathrm{~L}^{-1}$ of different supporting electrolytes: $\mathrm{HCl}$, acetate buffer, $\mathrm{KCl}$ and $\mathrm{KOH}$. To accomplish that, the useful potential window was defined as the potential range in which background currents are smaller than $2 \mu \mathrm{A}$, according to the methodology used by Oliveira et $a l . .^{35}$ The cyclic voltammograms recorded with the PDMS-CPE in the different supporting electrolytes are presented in Figure 4.

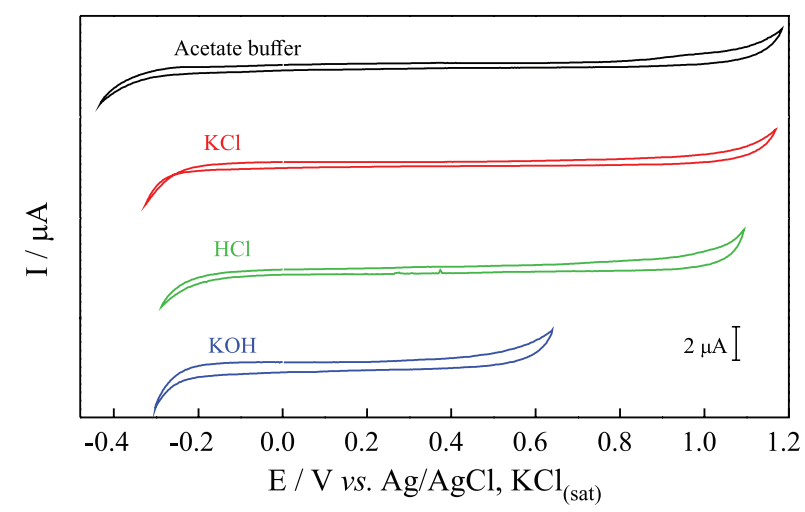

Figure 4. Cyclic voltammograms recorded with PDMS-CPE in $0.1 \mathrm{~mol} \mathrm{~L}^{-1}$ of different supporting electrolytes, $v=50 \mathrm{mV} \mathrm{s}^{-1}$.

Figure 4 shows that wide useful potential windows were observed for PDMS-CPE in all the studied supporting electrolytes. The narrowest potential window was found in $0.1 \mathrm{~mol} \mathrm{~L}^{-1} \mathrm{KOH}$, which is in close agreement with the previously reported for silicone-rubber CPEs. ${ }^{35}$ The useful potential windows observed in the other supporting electrolytes were close to $1.5 \mathrm{~V}$, and they are comparable with the potential window obtained with silicone-rubber ${ }^{35}$ and solid-paraffin ${ }^{8}$ CPEs. $\mathrm{Nujol}^{\circledR}$-CPE has presented narrower useful potential window and higher background currents regardless of the supporting electrolyte (Figure S4, SI section). It was observed that, for all evaluated supporting 
electrolyte, the voltammetric profile of PDMS-CPE remains unchanged even after 20 continuous potential cycling in the useful potential window. This behavior is indicative that PDMS-CPE presents high electrochemical/chemical stability in these aqueous solutions.

The electrochemical/chemical stability of PDMS-CPE was also evaluated in the mixtures $0.1 \mathrm{~mol} \mathrm{~L}^{-1} \mathrm{KCl}$ :ethanol and $0.1 \mathrm{~mol} \mathrm{~L}^{-1} \mathrm{KCl}$ :methanol, both in the proportion $1: 1(\mathrm{v} / \mathrm{v})$. The cyclic voltammograms recorded in these mixtures with PDMS and $\mathrm{Nujol}^{\circledR}{ }_{-} \mathrm{CPE}$ are presented in Figure 5.

Figure 5 shows that the voltammetric profile of $\mathrm{Nujol}^{\circledR}-\mathrm{CPE}$ in both mixtures was close to the expected for a resistor, i.e., a straight line as predicted by the Ohm's law. This behavior indicates that the electrical resistance of this electrode is high, which can be ascribed to the solubility of $\mathrm{Nujol}^{\circledR}$ in ethanol and methanol, leading to the electrode desegregation and electrical resistance increasing. After recording 20 potential cycles, a significant amount of graphite powder could be observed at the bottom of the electrochemical cell, confirming the electrode desegregation. The situation was entirely different for the PDMS-CPE, which presented a much better voltammetric profile with low and stable background currents. In addition, after 20 potential cycling, graphite particles were not accumulated at the bottom of the electrochemical cell. This behavior indicates that PDMS-CPEs did not suffer desegregation in the presence of the ethanol and methanol, which is consistent with the insolubility of PDMS in these solvents. Therefore, all these results show that PDMS is a better binder agent than $\mathrm{Nujol}^{\circledR}$, producing a more-

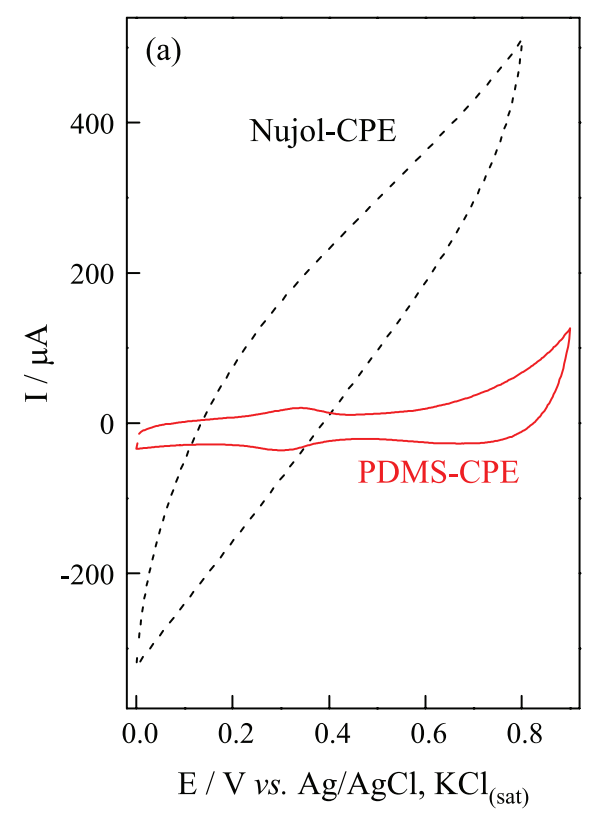

conductive and stable CPE even in the presence of ethanol and methanol. Figure 5a shows a pair of voltammetric peaks at approximately $0.3 \mathrm{~V}$. We could not identify the origin of these peaks, but they could be associated with impurities from the ethanol (metal ions, for example). However, additional studies should be performed to confirm this hypothesis.

\section{Analytical studies in the presence of PROP}

The quantification of PROP was performed by DPV with the following optimized voltammetric parameters: pulse amplitude $=50 \mathrm{mV}$, pulse width $=25 \mathrm{~ms}$, step potential $=2 \mathrm{mV}$ and $v=10 \mathrm{mV} \mathrm{s}^{-1}$. The electrooxidation of PROP is a pH-dependent process ${ }^{34}$ (Figure S5, SI section). Two possible mechanisms are proposed in the literature for PROP electrooxidation. The first one involves the hydroxyl group and the second considers the oxidation of the secondary amine group, and both reactions involve the same number of protons and electrons. ${ }^{34,36}$ The two voltammetric peaks observed at $\mathrm{pH}=8.0$ could be indicative that, depending on the $\mathrm{pH}$, PROP oxidation takes place on both groups: hydroxyl and secondary amine, as proposed by Santos and Cavalheiro. ${ }^{34}$ As can be observed from Figure S5 (SI section), the best voltammetric profile and peak intensity were obtained in BR buffer solution with $\mathrm{pH}=2.0$, which was selected for the subsequent studies.

DP voltammograms recorded with PDMS-CPE in the absence and presence of $50 \mu \mathrm{mol} \mathrm{L}^{-1} \mathrm{PROP}$ are presented in Figure S6 (SI section). As can be seen, the electrochemical

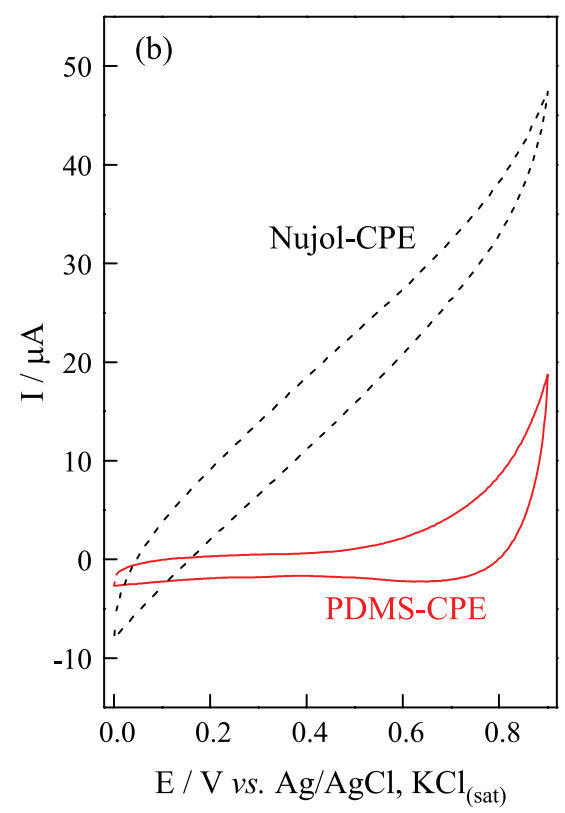

Figure 5. Cyclic voltammograms recorded at $100 \mathrm{mV} \mathrm{s}^{-1}$ in the mixtures (a) $0.1 \mathrm{~mol} \mathrm{~L}^{-1} \mathrm{KCl}$ :ethanol and (b) $0.1 \mathrm{~mol} \mathrm{~L}^{-1} \mathrm{KCl}_{\text {:methanol. }}$ 
oxidation of PROP gives an anodic peak at $1.08 \mathrm{~V}$, which is ascribed to the chemical reaction presented in Figure $6 .{ }^{34}$

Intra and inter-day precisions were evaluated in the presence of $50 \mu \mathrm{mol} \mathrm{L}{ }^{-1}$ PROP and were 3.4 and $9.7 \%$, respectively. Under the optimized conditions, DP voltammograms were recorded in different concentrations of PROP using both PDMS and $\mathrm{Nujol}^{\circledR}-\mathrm{CPE}$, as presented in Figure 7.

Figure 7 shows that PDMS-CPE presented more intense voltammetric peaks for PROP than Nujol ${ }^{\circledR}-\mathrm{CPE}$. The $\mathrm{i}_{\text {pa }}$ values from Figure 7 were used to construct analytical curves for PROP as shown in Figure 8a. Figure $8 \mathrm{~b}$ shows the analytical curve using the current density (j) as the analytical signal.

The analytical curves for both electrodes were linear from 10 to $60 \mu \mathrm{mol} \mathrm{L}{ }^{-1}$ PROP. The linear equations for these curves were: $\mathrm{i}_{\mathrm{pa}}(\mu \mathrm{A})=-0.180+0.078 \mathrm{C}_{\mathrm{PROP}}\left(\mu \mathrm{mol} \mathrm{L}^{-1}\right)$, $\mathrm{r}^{2}=0.997$ for PDMS-CPE and $\mathrm{i}_{\mathrm{pa}}=-0.026+0.049 \mathrm{C}_{\mathrm{PROP}}$ $\left(\mu \mathrm{mol} \mathrm{L}{ }^{-1}\right), \mathrm{r}^{2}=0.981$, for $\mathrm{Nujol}^{\circledR}{ }_{-\mathrm{CPE}}$. These results show that PDMS-CPE not only presented better linearity but also increased the sensitivity in 59\% compared with
$\mathrm{Nujol}^{\circledR}$-CPE. Figure $8 \mathrm{~b}$ shows that when $\mathrm{j}$ is used as the analytical signal the slopes of the analytical curves for both electrodes differ only by $10 \%$. This result indicates that most of the gain in the sensitivity provided by PDMS-CPE is due to its higher active electroanalytical area compared with $\mathrm{Nujol}^{\circledR}$-CPE.

The limit of detection (LOD) and the limit of quantification (LOQ) were estimated from the equations: $\mathrm{LOD}=3 \mathrm{sd} / \mathrm{b}$ and $\mathrm{LOQ}=10 \mathrm{sd} / \mathrm{b}$, where $\mathrm{b}$ is the slope of the analytical curve and sd is the standard deviation for the signal of blank, which was estimated from the error of the intercept of the analytical curve. ${ }^{6}$ For PDMS-CPE it was obtained LOD $=3 \mu \mathrm{mol} \mathrm{L}{ }^{-1}$ and LOQ $=10 \mu \mathrm{mol} \mathrm{L} \mathrm{L}^{-1}$,

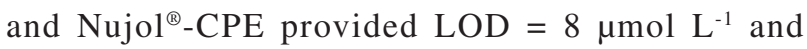
$\mathrm{LOQ}=27 \mu \mathrm{mol} \mathrm{L}{ }^{-1}$. From Figure 8 , it can be observed that the precision of the $i_{p}$ values obtained with the PDMS-CPE was superior to $\mathrm{Nujol}^{\circledR}{ }^{\circledR} \mathrm{CPE}$, which can be visualized by the larger error bars presented by $\mathrm{Nujol}^{\circledR}$-CPE. Therefore, the overall analytical performance of the PDMS-CPE for PROP quantification was better than $\mathrm{Nujol}^{\circledR}$-CPE. Table 1 shows a comparison between some analytical parameters obtained<smiles>C=CC(C)NCC(O)COc1cccc2ccccc12</smiles><smiles>CC(C)NCC(=O)COc1cccc2ccccc12</smiles>

Figure 6. PROP oxidation reaction.
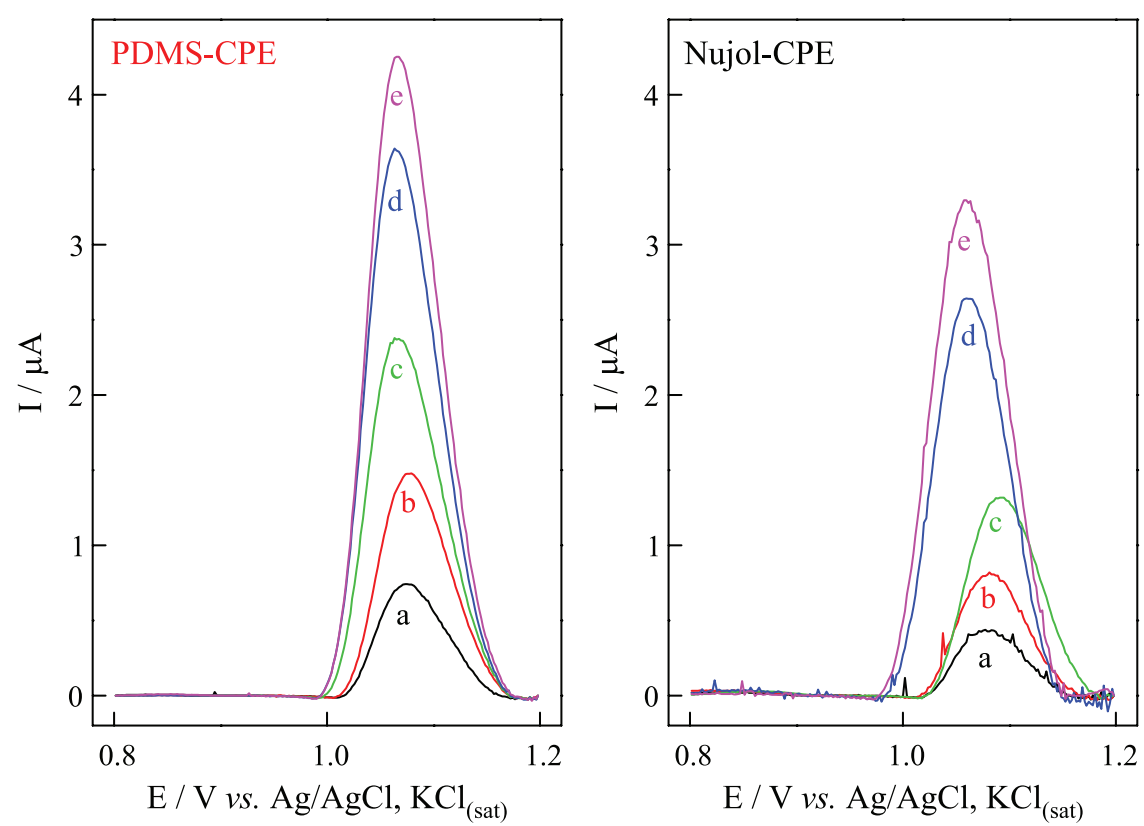

Figure 7. Baseline corrected DP voltammograms recorded in $0.04 \mathrm{~mol} \mathrm{~L}^{-1} \mathrm{BR}$ buffer solution ( $\mathrm{pH}=2.0$ ) in different concentrations of PROP: (a) 10; (b) 20; (c) 30; (d) 50 and (e) $60 \mu \mathrm{mol} \mathrm{L}{ }^{-1}$. Voltammetric conditions: pulse amplitude $=50 \mathrm{mV}$, pulse width $=25 \mathrm{~ms}$, step potential $=2 \mathrm{mV}$ and $v=10 \mathrm{mV} \mathrm{s}{ }^{-1}$. Peak potential for PROP $=1.08 \mathrm{~V}$. 

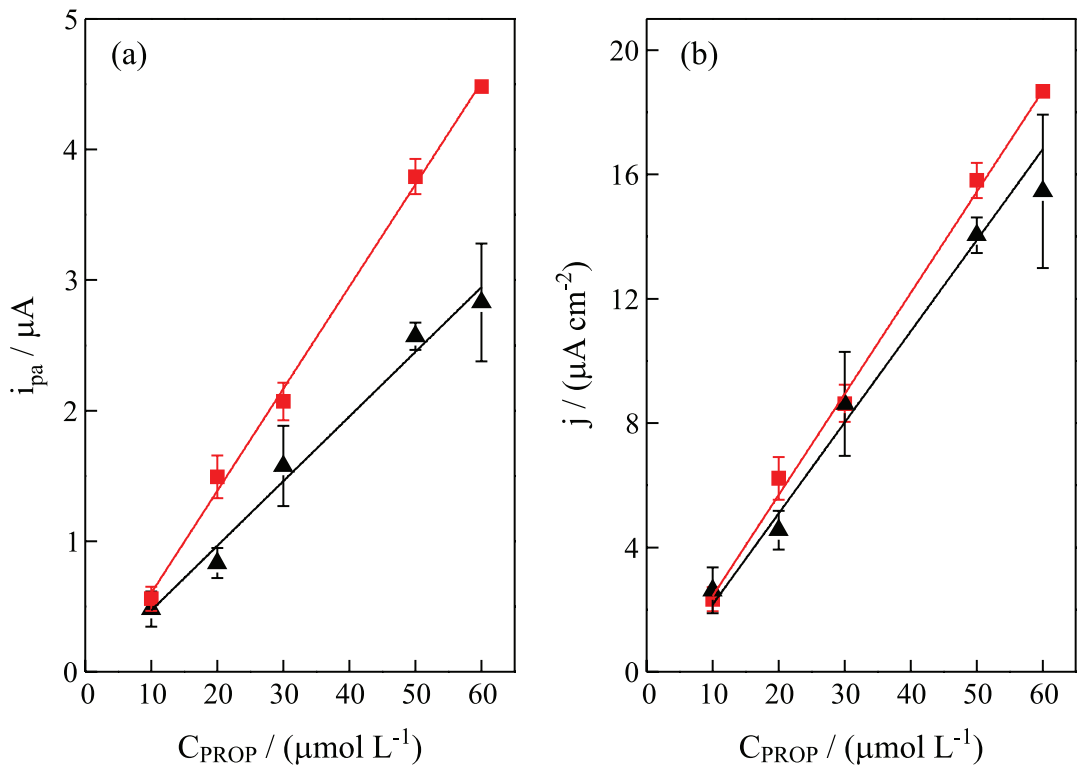

Figure 8. Analytical curves for PROP constructed with PDMS-CPE

) and $\mathrm{Nujol}^{\circledR}{ }^{\circledR} \mathrm{CPE}(\mathbf{\Delta})$, using (a) $\mathrm{i}_{\mathrm{pa}}$ and (b) j as the analytical signal.

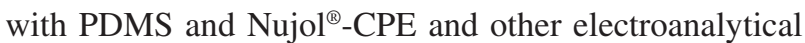
methods previously proposed for PROP determination.

Table 1 shows that the analytical performance of PDMS-CPE is inferior to the chemically modified and boron-doped diamond (BDD) electrodes. However, the PDMS-CPE can also be easily modified if improved analytical performance is required, which is not the case for pharmaceutical formulation samples. When BDD is coupled with MPA-BIA (multiple pulse amperometric detection batch injection analysis), it provides the same linear range with a lower LOD. The combination of BDD and square wave voltammetry (SWV) leads to a much better linear range and LOD compared with PDMS-CPE. Despite the superior analytical performance of BDD, this material is more expensive and less commercially available than graphite powder and PDMS. The analytical performance of PDMS-CPE was slightly inferior to silicone-rubber CPE. However, PDMS-CPE can be prepared in a faster way without the necessity of curing process. Therefore, the PDMS-CPE is a promising electrode material to be used with or without chemical modification in electroanalysis.

Table 1. Analytical parameters of some electroanalytical methods proposed for PROP quantification

\begin{tabular}{|c|c|c|c|c|}
\hline Electrode type & Electrochemical technique & $\begin{array}{c}\text { Linear range / } \\
\left.(\mu \mathrm{mol} \mathrm{L})^{-1}\right)\end{array}$ & $\begin{array}{c}\text { LOD / } \\
\left.(\mu \mathrm{mol} \mathrm{L})^{-1}\right)\end{array}$ & Reference \\
\hline CNT-PHA/GCE & AdAS-DPV & $0.074-1$ & 0.026 & 47 \\
\hline AgNP-IL-FG/GCE & SWV & $0.1-2.9$ & 0.017 & 48 \\
\hline CuNPs- GO-CB-PEDOT:PSS/GCE & SWV & $0.5-2.9$ & 0.18 & 49 \\
\hline BDD & MPA-BIA & $10-60$ & 0.17 & 46 \\
\hline BDD & SWV & $0.2-9.0$ & 0.18 & 51 \\
\hline$\gamma$-CD-CNT-CPE & AdAS-DPV & $0.14-48$ & 0.04 & 52 \\
\hline \multirow[t]{2}{*}{ CNT-silicone-rubber-CPE } & DPV & $0.5-7.0$ & 0.12 & 60 \\
\hline & SWV & $0.3-5.4$ & 0.078 & \\
\hline Silicone-rubber-CPE & DPV & $5-81$ & 1 & 34 \\
\hline $\mathrm{Nujol}^{\circledR}-\mathrm{CPE}$ & DPV & $10-60$ & 8 & this work \\
\hline PDMS-CPE & DPV & $10-60$ & 3 & this work \\
\hline
\end{tabular}

LOD: limit of detection; CNT: carbon nanotubes; PHA: poly-allylamine hydrochloride; GCE: glassy carbon electrode; AdAS: adsorptive anodic stripping; DPV: differential pulse voltammetry; AgNP: silver nanoparticles; IL: ionic liquid; FG: functionalized graphene; SWV: square wave voltammetry; CuNPs: copper nanoparticles; GO: graphene oxide; CB: carbon black; PEDOT:PSS: poly(3,4-ethylenedioxythiophene)-poly(styrenesulfonate); BDD: boron-doped diamond; MPA-BIA: multiple pulse amperometric detection batch injection analysis; CD: cyclodextrin; CPE: carbon paste electrode; PDMS: polydimethylsiloxane. 
Table 2. Results of PROP determination in pharmaceutical formulation samples using PDMS-CPE and the spectrophotometric official method ${ }^{53}$

\begin{tabular}{|c|c|c|c|c|c|}
\hline Sample & Labeled value / (mg per tablet) & PDMS-CPE ${ }^{\mathrm{a}}$ ( $\mathrm{mg}$ per tablet) & $\begin{array}{l}\text { Spectrophotometric }{ }^{\mathrm{a}} \\
\quad(\mathrm{mg} \text { per tablet })\end{array}$ & $F^{\mathrm{b}}$ & $t^{\mathrm{c}}$ \\
\hline A & \multirow{4}{*}{40} & $41 \pm 2$ & $40 \pm 1$ & 4 & 1.0 \\
\hline B & & $38 \pm 3$ & $40 \pm 1$ & 9 & 1.3 \\
\hline $\mathrm{C}$ & & $39 \pm 1$ & $38 \pm 1$ & 1 & 0.2 \\
\hline $\mathrm{D}$ & & $40 \pm 1$ & $40 \pm 1$ & 1 & 1.1 \\
\hline
\end{tabular}

${ }^{a}$ Values expressed as mean value \pm standard deviation; ${ }^{\mathrm{b}} F_{2 / 2}=39 ;{ }^{61}{ }^{\mathrm{c}} t=2.78\left(p=0.05\right.$ and 4 degrees of freedom) ${ }^{61}$ PDMS-CPE: polydimethylsiloxanecarbon paste electrode.

Aiming to evaluate the ability of the PDMS-CPE to quantify PROP in real samples, commercial pharmaceutical formulations were analyzed with these electrodes. All determinations were performed in triplicate and quantifications were carried out using the analytical curve equation. Table 2 summarizes the results of the sample analyses.

As shown in Table 2, the $F$ and $t$ values did not exceed the critical values, indicating that the precision and the results from DPV/PDMS-CPE and the spectrophotometric method are statistically equivalent. This result is a good evidence of the accuracy of the results provided by the PDMS-CPE. Therefore, the analytical performance provided by the PDMS-CPE allows reliable PROP quantification in commercial pharmaceutical formulation samples.

\section{Conclusions}

This study showed that CPEs prepared with uncured PDMS as binder agent presented higher electrical conductivity and higher active electrochemical area than $\mathrm{Nujol}^{\circledR}{ }^{\circledR} \mathrm{CPEs}$. Moreover, the PDMS-CPEs were more resistant to aqueous solutions containing $50 \%(\mathrm{v} / \mathrm{v})$ of ethanol or methanol compared with $\mathrm{Nujol}^{{ }^{\circledR}}$ - CPEs, which suffered desegregation in these solutions. The analytical performance of PDMS-CPEs was evaluated using PROP as a model analyte, and the results showed that these electrodes provided higher sensitivity and lower LOD than $\mathrm{Nujol}^{{ }^{\circledR}}$-CPEs. It was verified that most of this gain in sensitivity is ascribed to the higher active electrochemical area of PDMS-CPE compared with $\mathrm{Nujol}^{\circledR}$-CPE. Therefore, this study demonstrated that uncured PDMS could advantageously replaces $\mathrm{Nujol}^{\circledR}$ to produce CPEs with superior analytical/electrochemical performance compared to $\mathrm{Nujol}^{\circledR}$-CPEs. Obviously, the PDMS-CPE is not competitive with chemically modified or BDD electrodes for PROP determination. However, the analytical performance of PDMS-CPE can be modulated by properly modifying this electrode depending on the analytical problem. The higher stability of PDMS-CPEs in organic solvents suggests that these electrodes could be used as amperometric detectors in liquid chromatography or coupled to liquid-liquid extraction procedures, leading to more selective analytical methods.

\section{Supplementary Information}

Supplementary information is available free of charge at http://jbcs.sbq.org.br as PDF file.

\section{Acknowledgments}

The authors are grateful to FAPEMIG (APQ-02905-15 and APQ-02078-15), CNPq (447668/2014-5 and 443315/2014-0), FINEP (MCT/Finep/CT-INFRA 01/2010 and 01/2013) and CAPES for financial support. D. A. G. A., L. A. P.-F. and A. L. R. S. thank CAPES for the scholarships. The authors would like to acknowledge the Multiuser Laboratory of Chemistry Institute at the Universidade Federal de Uberlândia for providing the equipment and technical support for experiments involving electron microscopy.

\section{References}

1. Svancara, I.; Vytras, K.; Kalcher, K.; Walcarius, A.; Wang, J.; Electroanalysis 2009, 21, 7.

2. Svancara, I.; Walcarius, A.; Kalcher, K.; Vytras, K.; Cent. Eur. J. Chem. 2009, 7, 598.

3. Zimi, J.; Svancara, I.; Barek, J.; Vytras, K.; Rev. Anal. Chem. 2009, 34, 204.

4. Adams, R. N.; Anal. Chem. 1958, 30, 1576.

5. Svancara, I.; Kalcher, K.; Walcarius, A.; Vytras, K.; Electroanalysis with Carbon Paste Electrodes; CRC Press: New York, USA, 2012.

6. Fonseca, W. T.; Ribeiro, L. A. R.; Pradela-Filho, L. A.; Takeuchi, R. M.; Santos, A. L.; J. Braz. Chem. Soc. 2018, 29, 2466.

7. Oliveira, P. R.; Lamy-Mendes, A. C.; Gogola, J. L.; Mangrich, A. S.; Marcolino Jr., L. H.; Bergamini, M. F.; Electrochim. Acta 2015, 151, 525 . 
8. Silva, D. H.; Costa, D. A.; Takeuchi, R. M.; Santos, A. L.; J. Braz. Chem. Soc. 2011, 22, 1727.

9. Cesarino, I.; Marino, G.; Matos, J. R.; Cavalheiro, E. T. G.; J. Braz. Chem. Soc. 2007, 18, 810.

10. Cesarino, I.; Brett, C. M. A.; Cavalheiro, E. T. G.; Microchim. Acta 2010, 171, 1 .

11. Costa, D. A.; Takeuchi, R. M.; Santos, A. L.; Int. J. Electrochem. Sci. 2011, 6, 6410.

12. Silveira, J. P. S.; Piovesan, J. V.; Spinelli, A.; Microchem. J. 2017, 133, 22.

13. Karimi-Maleh, H.; Hatami, M.; Moradi, R.; Khalilzadeh, M. A.; Sedighe, A.; Sadeghifar, H.; Microchim. Acta 2016, 183, 2957.

14. Hassaninejad-Darzi, S. K.; Shajie, F. A.; J. Braz. Chem. Soc. 2017, 28, 529.

15. Raymundo-Pereira, P. A.; Teixeira, M. F. S.; Caetano, F. R.; Bergamini, M. F.; Marcolino Jr., L. H.; Electroanalysis 2015, 27, 2371.

16. Cazula, B. B.; Lazarin, A. M.; Mater. Chem. Phys. 2017, 186, 470.

17. Liang, Z.; Zhai, H.; Chen, Z.; Wang, S.; Wang, H.; Wang, S.; Sens. Actuators, B 2017, 244, 897.

18. Walcarius, A.; Sibottier, E.; Electroanalysis 2005, 17, 1716.

19. Divasar, F.; Isapour, N.; Kefayati, H.; Badiei, A.; Nezhadali, A.; Easapour, S.; Yadavi, M.; J. Porous Mater. 2015, 22, 1655.

20. Akbarian, Y.; Shabani-Nooshabadi, M.; Karimi-Maleh, H.; Sens. Actuators, B 2018, 273, 228.

21. Alavi-Tabari, S. A. R.; Khalilzadeh, M. A.; Karimi-Maleh, H.; J. Electroanal. Chem. 2018, 811, 84.

22. Santos, A. L.; Batista, E. A.; Gonçalves, L. M.; Sotomayor, M. P. T.; Int. J. Environ. Anal. Chem. 2017, 97, 159.

23. Tahernejad-Javazmi, F.; Shabani-Nooshabadi, M.; KarimiMaleh, H.; Talanta 2018, 176, 208.

24. Petit, C.; Gonzalez-Cortes, A.; Kauffmann, J.-M.; Talanta 1995, 42, 1783.

25. Fatibello-Filho, O.; Vieira, I. C.; Talanta 2000, 52, 681.

26. Baccarin, M.; Cervini, P.; Cavalheiro, E. T. G.; Talanta 2018, $178,1024$.

27. Calixto, C. M. F.; Cavalheiro, E. T. G.; Anal. Lett. 2017, 50, 2323.

28. Santos, S. X.; Cavalheiro, E. T. G.; Anal. Lett. 2016, 49, 1543.

29. Ferreira, A. P. G.; Cervini, P.; Calefi, R. M.; Claro-Neto, S.; Cavalheiro, E. T. G.; Braz. J. Therm. Anal. 2015, 3, 55.

30. Calixto, C. M. F.; Santos, S. X.; Cavalheiro, E. T. G.; Quim. Nova 2014, 37, 367.

31. Silva, R. B. A.; Rabelo, A. C.; Bottechia, O. L.; Munoz, R. A. A.; Richter, E. M.; Quim. Nova 2010, 33, 1398.

32. Serra, B.; Reviejo, A. J.; Parrado, C.; Pingarrón, J. M.; Biosens. Bioelectron. 1999, 14, 505.

33. Diego, E.; Aguí, L.; Gonzáles-Cortés, A.; Yañez-Sedeño, P.; Pingarrón, J. M.; Kauffmann, J.-M.; Electroanalysis 1998, 10, 33.
34. Santos, S. X.; Cavalheiro, E. T. G.; Anal. Lett. 2011, 44, 850.

35. Oliveira, A. C.; Santos, S. X.; Cavalheiro, E. T. G.; Talanta 2008, 74, 1043.

36. Sousa, R. A.; Santos, S. X.; Cavalheiro, E. T. G.; Brett, C. M. A.; Electroanalysis 2013, 25, 706.

37. Owen, M. J. In Encyclopedia of Materials: Science and Technology, $2^{\text {nd }}$ ed.; Buschow K. H. J., ed.; Elsevier: Oxford, 2001, p. 2480.

38. Kulys, J.; Krikstopaitis, K.; Ruzgas, T.; Razumas, V.; Mater. Sci. Eng., C 1995, 3, 51.

39. Wang, J.; Li, S.; Moa, J.-W.; Porter, J.; Musameh, M. M.; Dasgupta, P. K.; Biosens. Bioelectron. 2002, 17, 999.

40. Silva, R. P. D.; Lucho, A. M. S.; Pissetti, F. L.; J. Braz. Chem. Soc. 2018, 29, 1761.

41. Brun, M.; Chateaux, J.-F.; Deman, A.-L.; Pittet, P.; Ferrigno, R.; Electroanalysis 2011, 23, 321.

42. Sameenoi, Y.; Mensack, M. M.; Boonsong, K.; Ewing, R.; Dungchai, W.; Chailapakul, O.; Cropeke, D. M.; Henry, C. S.; Analyst 2011, 136, 3177.

43. Partani, P.; Modhave, Y.; Gurule, S.; Khuroo, A.; Monif, T.; J. Pharm. Biomed. Anal. 2009, 50, 966.

44. El-Emam, A. A.; Belal, F. F.; Moustafa, M. A.; Elashry, S. M.; El-Sherbiny, D. T.; Hansen, S. H.; Il Farmaco 2003, 58, 1179.

45. Idowu, O. S.; Adegoke, O. A.; Olaniyi, A. A.; J. AOAC Int. 2004, 87, 573.

46. Gimenes, D. T.; Marra, M. C.; Munoz, R. A. A.; Angnes, L.; Richter, E. M.; Anal. Methods 2014, 6, 3261.

47. Oliveira, G. G.; Vicentini, F. C.; Azzi, D. C.; Sartori, E. R.; Fatibello-Filho, O.; J. Electroanal. Chem. 2013, 708, 73.

48. Santos, A. M.; Wong, A.; Fatibello-Filho, O.; J. Electroanal. Chem. 2018, 824, 1.

49. Wong, A.; Santos, A. M.; Silva, T. A.; Fatibello-Filho, O.; Talanta 2018, 183, 329.

50. Zilberg, R. A.; Sidelnikov, A. V.; Maistrenko, V. N.; Yarkaeva, Y. A.; Khamitov, E. M.; Kornilov, V. M.; Maksutova, E. I.; Electroanalysis 2018, 30, 619.

51. Sartori, E. R.; Medeiros, R. A.; Rocha, R. C.; Fatibello-Filho, O.; Talanta 2010, 81, 1418.

52. Gaichore, R. R.; Srivastava, A. K.; J. Inclusion Phenom. Macrocyclic Chem. 2014, 78, 78.

53. Agência Nacional de Vigilância Sanitária (ANVISA); Brazilian Pharmacopoeia, vol. 2, $5^{\text {th }}$ ed.; ANVISA: Brasília, Brasil, 2010, p. 859.

54. Franco, M. A.; Araújo, D. A. G.; Oliveira, L. H.; Trindade, M. A. G.; Takeuchi, R. M.; Santos, A. L.; Anal. Methods 2016, 8, 8420.

55. Ribeiro, L. A. R.; Pradela-Filho, L. A.; Fonseca, W. T.; Araújo, D. A. G.; Assunção, R. M. N.; Takeuchi, R. M.; Santos, A. L.; Anal. Methods 2017, 9, 3831.

56. Bard, A. J.; Faulkner, L. R.; Electrochemical Methods Fundamentals and Applications, $2^{\text {nd }}$ ed.; John Wiley \& Sons: New York, USA, 2001. 
57. Pradela-Filho, L. A.; Araújo, D. A. G.; Takeuchi, R. M.; Santos, A. L.; Electrochim. Acta 2017, 258, 786.

58. Kushikawa, R. T.; Silva, M. R.; Angelo, A. C. D.; Teixeira, M. F. S.; Sens. Actuators, B 2016, 228, 207.

59. Mosbach, M.; Laurell, T.; Nilsson, J.; Csoregi, E.; Schuhmann, W.; Anal. Chem. 2001, 73, 2468.
60. Santos, S. X.; Cavalheiro, E. T. G.; Brett, C. M. A.; Electroanalysis 2010, 22, 2776.

61. Miller, J. N.; Miller, J. C.; Statistics and Chemometrics for Analytical Chemistry, $6^{\text {th }}$ ed.; Pearson Education: Toronto, Canada, 2010.

Submitted: March 3, 2019

Published online: May 27, 2019 